\title{
AAATE Newsletter, Summer 2004
}

\section{FROM THE EDITOR}

Lawrence Normie LNormie@jdc.org.il

"Summertime, and the living is easy", according to George Gershwin. But perhaps not so easy for everyone. Summer vacation to tourist sites presents special challenges to those with disabilities. Potential impediments to a relaxing holiday are numerous: transportation, hotel accommodation, access to beach and recreation sites, etc.

To be sure, in several countries accessibility codes are recommended to be followed by the tourist industry, including operators of resort, hotel, infrastructure, and services. For example, the German Federal Ministry of Economic and Labour (BMWA) earlier this year published the report "Economic Impulses of Accessible Tourism", which suggests that "Besides the direct economic effects, the presence of an accessible infrastructure causes indirect impacts e.g. on the construction, crafts, and assistive and adaptive technology industries. Accessibility can hence become a crucial locational factor". The interesting implication here (with which I am not sure I entirely agree) is that one first needs to establish accessibility to the built environment before particular assistive technological solutions for tourists with disability can flourish commercially.

This matter also brings to mind the landmark position paper published by the European Disability Forum in 2001. The document, titled "EDF Position Paper on Tourism: Framing the Future of European Tourism" (Doc. EDF 01/13 EN) opens with the declaration that "EDF welcomes the intentions of the European Commission to progress a strategic and cooperative approach to tourism involving all stakeholders and consumer groups, including disabled people" and proceeded with a series of wide-ranging and far-reaching proposals. These included, notably, tourism as a social right, the business argument for accessible tourism, and the impact of information and communication technology (ICT) based services in the tourism sector. So, what has happened since?

Well, you should all be glad to know that the mandate to address tourism and disability is alive and well in the guise of Sixth Framework Programme (FP6) Information Societies technology (IST) Priority 2, which "supports research on technologies addressing the key security challenges posed by the "all-digital" world and the need to secure the rights and privacy of citizens; "ambient intelligence" systems offering access to the information society for all, regardless of age and situation (such as disability or other individual circumstances), as well as interactive and intelligent systems for health, mobility, security, leisure, tourism. ..”.

So how many FP6 projects right now actually are tackling the disability and tourism/leisure issue? Unfortunately, the FP6 web information service on CORDIS presently does not provide for searches of project details. But let us hope that the scope and scale of activities in this area for FP6 will be a substantial improvement upon FP5, where, according to the best of my knowledge, only 6 projects were initiated or completed in which the issue of accessible tourism was addressed in any form.

\section{PRESIDENT'S MESSAGE}

Harry Knops h.knops@irv.nl

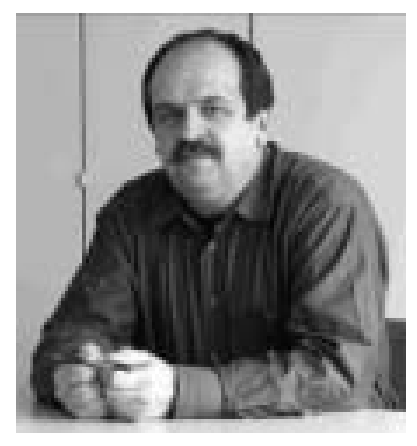

Dear AAATE Members, the last three months were very busy for the AAATE board. After our face to face meeting in March we had to start to work on actual issues.

The renewal of the membership is an annual repeating, but time consuming activity for the office in Denmark. I want to ask you all to answer to the request for update as soon as possible. Besides this, the start of two projects involving AAATE is energy consuming. I will report on the status later in my message. I also want to inform you on the international co-operation with RESJA and RESNA. 


\section{The CWST project}

In my message in the last Newsletter, I reported on the acceptance of the CWST project.

We passed the negotiations. I would very much like to thank Klaus Miesenberger for his excellent effort to start the project as soon as possible. From the negotiations we learnt that AAATE is not yet completely prepared for partnership in projects. At this moment, all the practicalities are clarified and we can start.

The first activity of the project will be the annual workshop of AAATE in November 2004. The main topic will be AT training and education and we want to exchange the current and stimulate future professional development in our sector.

The proposal is a combined workshop about education and training with the EdeAN network. Also our General Assembly will then take place. We will inform you as soon as possible about this activity.

\section{The AT award project}

AAATE plays an important role in the award project initiated by DG Employment and organised by Ogilvy in co-operation with FTB in Germany.

The AT award will be celebrated during the REHA exposition at Düsseldorf in November 2004. AAATE will chair the jury and members of our organisation will participate in the jury.

The call for innovations will be sent out soon and I want to encourage you all to send in innovations in the field of AT.

\section{International co-operation}

During the RESNA conference in June 2004, AAATE was asked to organise an international session on outcome assessment. In this session, an overview of the current situation was presented by me as an introduction to two excellent presentations by Jan Person (SWE) and Ase Brandt (DE). Both Jan and Ase presented the developments in their home countries from a different point of view. Outcome assessment is an important topic for our AT world. In Europe, Gert-Jan Gelderblom has taken the initiative to organise a SIG inside AAATE to stimulate development and exchange in the important area.

During RESNA, an agreement between RESNA and AAATE was signed to appoint co-editors in chief for the journals to stimulate exchange and participation. So AAATE will appoint a co-editor in chief for Assistive Technology and RESNA for Technology and Disability. In my opinion, this is another step forward to international exchange and co-operation.

\section{E-inclusion}

In a meeting with the management and officers of the office in Brussels, several issues were discussed. The office expects an active contribution of AAATE to the discussions for future planning in the EU. This is difficult to fulfil, but we will give it a try!

There is a positive attitude towards the co-operation with the AAATE and we are looking forward to the next call. The timing is not yet set.

Also we want to contact the new commissioner to introduce the AAATE to him.

\section{CVHI conference in Granada}

As president of AAATE, I was invited to give a keynote speech about the developments in AT in Europe. A great number of young researchers was present and gave presentations of their work. The quality and number of good presentations that were made at this conference were surprising in a positive way. I also want to congratulate Marion Hersch with this great result and performance which shows that there is an incoming group of young researchers in our field and that is the group that has to keep the sector alive in future!

Ending my message to you I want to wish you all a happy summer and relaxing holidays.

\section{NATIONAL NEWS}

\section{Reports from AAATE national contacts}

\section{Denmark}

\section{Erland WinterbergEWI@hmi.dk}

\section{Nordic Assisted Mobility Evaluation (NAME)}

The NAME project is in a phase in which the first version of the actual instrument has been developed. After this it has been discussed by a group of users of assistive technology for mobility and a group of experts in each of the five Nordic countries, and in Sweden also by a group of researchers within the area of assistive technology. The Danish expert group consisted of therapists from the municipal, the county and national level. A lot of relevant comments were received and Danish Centre has participated in the extensive audit. Next step is a translation and a pilot test, which will take place during this summer. The Danish Association of Occupational Therapists has contributed with 35,000 DKR, and The Municipal Tax Foundation has been applied for further funds. Read more about the project in AAATE's last Newsletter. 


\section{Publication of article in Journal of Rehabilitation Medicine}

Åse Brandt from Danish Centre has as the first writer had an article "Older people's use of powered wheelchairs for activity and participation" published in Journal of Rehabilitation Medicine.

\section{Nordic Seating Symposium}

The 2nd Nordic Seating Symposium was held in Oslo, Norway, in the end of April 2004. There were about 450 participants mainly from the Nordic countries, but also participants from Switzerland and Japan. The programme carried through as planned with two days of plenum lectures and one day of parallel sessions at which three different things took place simultaneously. The lecturers were from the Nordic countries and from England, Belgium, Canada and USA.

At the closing of the symposium the participants were introduced to the plans for the next symposium that is going to be held in Denmark in 2006 in DGIbyen in Copenhagen. The Danish Centre is the main organizer assisted by "The Nordic Seating Network" with a professional from each of the Nordic institutes.

A website has been developed on which users and professionals, who work with seating positions, can exchange experiences and look for information www.sitsite.net

\section{“COGAIN"}

The EU-project "COGAIN", which consists in forming a world-wide network on eye gaze systems, awaits the final decision from the EU. There is every indication that the project is going to get the grant. Danish Centre is in charge of a Work Package about dissemination. The project is going to start in September if the project gets the grant.

\section{Publication on the Nordic service delivery systems}

The publication on the Nordic service delivery systems, which has been published by NSH (Nordic Cooperation on Disability) in May 2003, has now been made in an English version. The publication is free and can be ordered by contacting the Danish Centre or it can be downloaded from NSH's website www.nsh.se.
New system for rehabilitation in Denmark

The Danish government has just presented a new proposal for a new structure for the dividing of the tasks between government level, regional level, and municipality level. The proposal implies that the conditions of providing rehabilitation in Denmark are improved by establishing a governmental institute with regional departments that unite the overall knowledge on the entire rehabilitation area (with the exception of the medical rehabilitation) in one organization. Danish Centre is going to be a part of this organization along with a number of other national and regional resource centres.

\section{Greece \\ Constantine Stephanidis cs@ics.forth.gr}

\section{Greek AT network launched}

EFTEHNOS is a national project funded by the General Secretariat for Research and Technology of the Hellenic Ministry of Development. The objective of the project is to develop a human network among academic and research partners, companies and organizations of people with disability, aiming to promote awareness for the adoption and widespread use of assistive technologies. This is accomplished through a series of seminars, taking place in various locations in Greece, which present methods and techniques for the application of IT\&T that support the socio-economic integration of people with disability. The target groups of these seminars are post-graduate students as well as professionals.

The project is co-ordinated by the National and Kapodestrian University of Athens. Contact: Prof. Georgios Kouroupetroglou, koupe@di.uoa.gr. www. di.uoa.gr/speech/eftehnos.

\section{Conference on AT and employment}

A three-day conference entitled "Assistive Technologies for People with Disabilities" was organized by the Development Partnership PROKLISI www.proklisi.gr funded in the context of the EQUAL initiative of the European Commission (17-19 May 2004 in Heraklion, Crete). The project aims to develop and promote methods and practices that will facilitate the employment of people who face discrimination in the labour market due to a disability condition. PROKLISI is also member of the TELA transnational network www.telanet.org where four development partnerships are in- 
volved. The overall objective of the network is the improvement of the employability of people with disability.

\section{Italy}

\section{Developments in Assistive Technology policies}

\section{Renzo Andrich renzo.andrich@siva.it}

Exposanità, a major Fair on Health Care was held in Bologna on May 12-15 offering the largest exhibition of Assistive Technology products ever held in Italy.

Besides providing a comprehensive and exciting showcase of the current market offer and innovation, the Fair gave also the opportunity for industrialists, suppliers and technicians to express their concern on the current situation in the public service delivery system. Due to a number of factors, including the recent political shift towards regional federalism also in matters related to Health care, the national Directory of assistive devices provided by the National Health Service is not being updated since several years. This means that a wide range of fundamental devices is not yet included the list - thus not affordable to users that cannot pay for them - and many other devices are allocated inadequate payment schemes.

However, there are signals that the situation may begin to change. Recent pieces of legislation clarify that ensuring the so-called "essential levels of care" (LEAs) is a task of the State, although each Region may decide to provide locally additional levels on their own resources. What's important is that assistive technologies have been acknowledged as falling within the LEAs. Therefore the Ministry of Health (in collaboration with the Regions) is going to establish a technical commission charged with revising and updating the service delivery system.

As a basis for that work, the Ministry decided to adopt and publish the findings of a research carried out by the Fondazione Don Carlo Gnocchi Onlus in the period 2002-2003. Such findings include a methodological document that sets the scientific basis for a new national directory; a proposed new directory, covering around 1800 items; and a software tool for the future maintenance and update of the directory. On this ground, the new Ministerial commission will work at designing a new scenario.

\section{New GLIC web site}

\section{Claudio Bitelliglic@ centriausili.it}

The new website of GLIC - the Italian network of information/advice centres on electronic Assistive De- vices - is now online at www.centriausili.it. Membership of GLIC is open to all AT Centres that do not directly commercialise assistive devices, but rather provide - independently on commercial interest - information, assessment, support, training directly to people with disabilities and professionals. Many GLIC members are involved in research projects as well. The main goals of the website are:

- To provide information on non-commercial AT centres in Italy, on events of interest for those who, at various level, work in Italy in the Assistive Technologies field.

- To provide links to institutions, market actors and other resources on the Internet.

- To serve as a virtual joint working space for the member centres where they can exchange information, technical details, free software, documentation, etc.

- To provide forum facilities to the entire community of users and professionals in the field of AT, so as to stimulate debate and to facilitate the exchange of information among them.

The web site is completely accessible and a section in English will be added within the near future. Looking forward to your visit, comments, and contributions.

\section{Finland}

Juha Hautanen juha.hautanen@jypoly.fi

Finnish-Swedish international intensive course in assistive technology

\section{By Kari Vehmaskoski from Jyväskylä Polytechnic}

This international course was organised by Jyväskylä Polytechnic of Finland. Besides Finland, participants came from European universities and technical colleges in the Netherlands, Germany, Portugal, and Denmark. Altogether there were 23 students and lecturers. All participants had a background in physiotherapy or in occupational therapy degree programmes.

The course was mainly supported by EU SocratesErasmus programme and was related to the thematic year of the disabled people 2003 .

One purpose of the course was to offer more technically orientated knowledge and to promote awareness among PTs and OTs concerning new technology and its possibilities to support functional capacity and people's independence.

Several commercial enterprises and research institutions supported the course both in Finland and in 
Sweden. Finnish institutions such as STAKES (National Research and Development Centre for Welfare and Health), the Peurunka Rehabilitation and Physical Exercise Centre, and the Finnish Association of people with Mobility Disabilities were also involved. The latter organisation provided the possibility to see real assistive technology in real active use by people with disabilities.

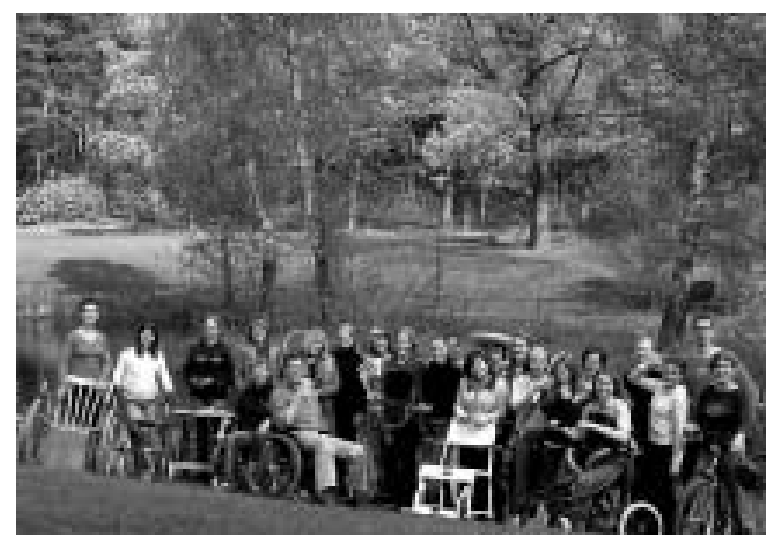

Innovative Finnish companies like Pikosystems Ltd., Emfit Ltd., and PhysioTools Ltd. offered ideas and applications how to use new technology with aged and disabled people. One day was dedicated to "Wellness Technology", with international lecturers participating.

After a week in Finland the group travelled by sea to Stockholm. The course participants found it both instructive and interesting to visit Swedish organisations and observe the process of the selection of assistive technology.

The Swedish Handicap Institute has traditionally cooperated in these courses together with Jyväskylä Polytechnic. During this visit, environmental control technology in smart houses linked was demonstrated, as well as new innovations in the laboratory.

Swedish enterprise CA Mätsystem introduced their wheelchair products for prevention of decubitus ulcers with the help of pressure measurements.

At the end of the course, all students expressed that they learned a lot and the period offered them a unique possibility to obtain a more detailed and, on the other hand also a broader, perspective of assistive technology. One important thing is that they will take this information and experience back to their home universities. The opportunity during this intensive course for interaction with colleagues from different countries also was an important learning experience for the participants.

Jyväskylä Polytechnic/Degree Programme in Physiotherapy has offered several international intensive courses since1997. Two of these courses have been on assistive technology.

\section{Norway \\ Toril Bergerud Buene \\ Toril.BergerudBuene@shdir.no}

\section{Smart home technology in Norway - film and guidelines}

The Delta Centre www.shdir.no/deltasenteret is the National Resource Centre for Participation and Accessibility for persons with disabilities; it is part of the Directorate for Health and Social Affairs. The centre has conducted and participated in several surveys concerning the use of smart home technology as part of in-home health and social services.

In Norway there is a wide use of smart home technology in newly built residential flats, aiming at old residents in need of care. The last project on smart home technology investigated the possibilities, advantages and funding of smart home technology installed in existing housing for young disabled persons. As part of the project, Tom, a man with reduced mobility, had smart home technology installed in his flat.

The project is documented in a film called "Smart Home". The film introduces Tom who has the technology installed, and Anders, a young boy with reduced mobility. Anders is exploring the theme of smart home, with a view for his own future. He visits Tom, and learns about the technology and how it may contribute to independent living. The viewer gets a glimpse into the lives, dreams and playfulness of both boys. Smart home technology becomes a support to independent living for Tom, and Anders is hoping for the same in his life.

The film lasts for 22 minutes, and has English subtitles. For more information: Toril Laberg,tol@shdir.no.

\section{Guidelines to Smart Home Technology}

The Delta Centre published in 2001 "Guidelines to Smart Home Technology - Part 1", which gives a definition to smart home technology and presents ways of using it to support independent living. During autumn 2004 "Guidelines to Smart Home Technology - Part 2", will be published. Part 2 will be more detailed in the description on how to plan the installation, and areas to consider ensuring successful application of smart home technology.

The guidelines are available in Norwegian only. More information can be obtained from Toril Laberg, tol@shdir.no. 
Presentation of the handbook "Accessible meetings, courses and conferences - a tool for the all-inclusive organiser"

The Delta Centre believes that greater knowledge and awareness of an inclusive organisation of events is necessary, in order to enable people with disabilities in participating in meetings, conferences and training courses.

Participation for all requires paying attention to many factors. More than anything, it reflects a holistic approach to the challenge. The concept of 'universal design' takes into consideration the functional diversity among people.

The handbook provides a systematic collection of recommendations and information on a broad field of areas, all linked to accessibility. After introducing the concept of 'universal design', it gives an outline on topics to consider when planning, conducting and following up an event.

The handbook offers the organisers of meetings, conferences and training courses a checklist on accessibility, and also useful advice and information to moderators and speakers. It also describes the specific needs regarding accessibility, linked to various groups of disabilities.

The content of the handbook may be summarised into the following 10 topics:

1. How do the participants get to the venue?

2. Is the location accessible, regarding parking and entrance?

3. How is the gate (location) marked, outdoor and indoor?

4. How accessible are the meeting rooms and other premises?

5. How is the illumination?

6. How are the acoustics?

7. How is the indoor climate?

8. Are communication utilities available?

9. How are the safety procedures implemented?

10. Are the educational aspects for everybody considered?

"A toolkit" may describe the handbook, as it is intended to be a tool for everyone who is involved in organising large or small arrangements.

A paper and CD copy of the English version of the handbook can be ordered from trykksak@shdir.no and its electronic version may be accessed at: www.shdir. no/deltasenteret. For further information, contact: kristin.bille@shdir.no.

\section{Spain}

Ricard Barberà guillem ribargui@ibv.upv.es

HEART revision - eight years on

Last May, CEAPAT, IBV and ALIDES completed a project with the aim of evaluating the accomplishment of the HEART (Horizontal European Activities in Rehabilitation Technology) study recommendations, eight years after this study was performed in Europe. The objectives of the project, described in a report titled "The Future of Technologies for Disabled and Elderly People in Spain: Needs for Action”, were:

- To establish methodology to review implementation of the recommendations of the HEART Study that can be easily applied in all participating countries.

- To evaluate application of these recommendations in Spain, by consensus among a group of experts.

- To disseminate information on the progress achieved in Spain and the areas that should be developed in the future.

The results of the evaluation are summarised in the following table for the different action lines

Table 1

Average evaluations by HEART line and average overall evaluation

\begin{tabular}{lc}
\hline & $\begin{array}{c}\text { Average evaluation by line } \\
\text { of work in the HEART study }\end{array}$ \\
\hline Line"A" & 2.8 \\
Line"B" & 2.3 \\
Line"C" & 1.7 \\
Line"D" & 2.1 \\
Line"E" & 2.0 \\
Line"F" & 2.6 \\
Evaluation"Uc"* & 2.8 \\
Average overall evaluation & 2.3 \\
\hline
\end{tabular}

* "Uc": Users committee.

- LINE A: Standardisation and Evaluation of Products and Services;

- LINE B: Coherence in the relations between market agents based on these technologies;

- LINE C: Systems of provisions of Accessibility and Technical Aids;

- LINE D: Legal and Socio-economic aspects related to consumption;

- LINE E: Specialized training in the sector;

- LINE F: Research, Development and Innovation Activities;

- Line Uc: Evaluation of Recommendations by the Users Committee. 
The evaluation of the degree of sectorial development obtained a total average score of 2.3 points out of a maximum possible of 5 points. This score reflects the existence of significant advances in some lines of work, while there are other aspects that have not yet progressed sufficiently. The limited development of the Systems for Provision of Accessibility and Technical Aids is noteworthy. It prevents a greater market development, a broaden use of technical aids and a greater accessibility to the physical environment by users.

A PDF version of the results of this study is available both in English and in Spanish from Ricard Barberà Guillem ribargui@ibv.upv.es

\section{Hungary \\ Arato Andrasarato@sunserv.kfki.hu}

\section{Accessible electronic library}

The Hungarian Electronic Library is running national project for improving the accessibility of its web site (http://vmek.oszk.hu) not only for the blind but also for low vision and other text disabled people. The site contains setting possibilities for background and character colours, character size, and type. Navigation can be controlled with one-hand key commands (e.g., 'h' and not 'alt/h'). The customised settings and some search strings are stored for every user. First reactions from user test are promising.

\section{Speaking ATM}

The Magyarországi Volksbank in Budapest has introduced its first Hungarian speaking Electronic Teller Machine. Based upon an original development in the UK, the ETM system was adapted to the Hungarian language with recorded speech. For security reasons, ETM has an ordinary headphones input. Headphones can be borrowed during bank opening hours.

\section{MEMBERS’ NEWS}

Update on the European Assistive Technology Information Network

\section{Renzo Andrich renzo.andrich@siva.it}

The EASTIN website www.eastin.info has been online since May 2004 and is available in six languages. The European Assistive Technology Information Network - announced in the previous issue of this newslet- ter - arises from the experience and knowledge gained by partners in six European countries (Denmark, UK, Netherlands, Germany, Spain, and Italy) all active for several years as major information providers at national level.

Currently the EASTIN consortium is conducting a comparative analysis of the six national information systems that will set the ground for the second stage of the project i.e., planning how they can be better harmonised and integrated in view of working together as a unique network. National workshops will be held before October in each of the six member countries to introduce the EASTIN network to the public, especially to three main targets: end-users, health care professionals, and industrialists.

Other countries have expressed interest in joining this collaboration network. Of course, they cannot directly take part in EASTIN, it being a project cofunded by the European Commission as part of its eTEN programme. However, they may apply to join the World Alliance of Assistive Technology Information Providers, which is a voluntary association open to worldwide collaboration in the field. For more information, see http://siva.welfare.gov.it/ENG/servizi/iaatip .

European IST-STREP project MOVEMENT (modular versatile mobility enhancement technology)

\section{Gert Jan Gelderblom gj.gelderblom@irv.nl}

Personal mobility is an indispensable factor of human freedom, dignity, and quality of life. Changing from the "Industrial" to the "Information Society" also implies the freedom to move within information space, to have access to adequate IST tools, and to bridge the digital divide. Old and disabled people thus face a threefold barrier (a) having problems moving themselves; (b) having difficulties handling or moving objects; (c) living on the downside of the digital divide.

MOVEMENT aims at the development of a modular versatile mobility enhancement system. The core is formed by an intelligent mobile (robotic) platform, which can attach to or communicate with a userdefinable selection of application modules (e.g., chair, manipulator, and ICT terminal) which are more or less inconspicuous mainstream articles but will become powerful assistive devices when the mobile platform attaches to them. All three dimensions of personal mobility - MOVEMENT of People - MOVEMENT of Objects - MOVEMENT of Information - therefore are comprehensively addressed. 
The system is designed around our novel concept on "Modular Mobility" where dedicated modules (agents) facilitate open flexibility, operational stability, and cost reduction. Modules will be self-organizing in an innovative way by adapting to the current setup. Open interfaces will allow easy integration of existing assistive devices as well as development of application modules from third parties. An intuitive command interface supports the user by estimating his/her intention and automatically adapting to the current needs. The final result is an easy-to-use system with plug-and-play functionality for different kinds of user support, compatible also to the market demands.

The MOVEMENT consortium is led by FORTEC (TU Vienna) and includes eight partners from Austria, Germany, Switzerland, Italy, Belgium, and The Netherlands.

For more information, please contact the project leader Wolfgang Zagler (zw@fortec.tuwien.ac.at)

\section{ASSOCIATION MATTERS}

\section{News from AAATE's secretariat}

The secretariat has published a new information and promotion folder for AAATE. The new folder's design theme corresponds visually to the AAATE website. The folder describes AAATE's mission, work areas, and the advantages you get as a member of AAATE. The folder can be ordered by contacting Lone Juncker in the secretariat at lkj@hmi.dk.

\section{AAATE web site}

We encourage all members to use the website, as we attempt to put all relevant information there. If you have any questions please do not hesitate to contact Lone Junckerlkj@hmi.dk at the secretariat.

AAATE welcomes a new national contact!

\section{from Anna-Liisa Salminen}

anna-liisa.salminen@stakes.fi

A new person has joined our group of national contacts. Renata Hojanic has accepted to be the Croatian national contact of AAATE.

In Croatia there does not exist a separate association which promotes use of assistive technology. Renata works at the Department of Motoric Disturbances and Chronic Diseases in Faculty of Education and Rehabilitation Sciences, University of Zagreb. They are trying to promote use of assistive technology in education and rehabilitation. Renata hopes that cooperation with AAATE will help them in these efforts. Her e-mail address is: hojanic@erf.hr.

\section{FORTHCOMING EVENTS}

In this section, members are invited to submit announcements concerning meetings and events in the AT field. In addition, FAST UK (www.fastuk.org) provides a comprehensive, annotated, and long-range listing of future national and international events relating to AT and allied fields.

\section{ADDRESS BOOK}

\section{AAATE Board Members}

Harry Knops, President

IRV, Hoensbroek, The Netherlands

Tel.: +31 4552376 12; Fax: +31 4552315 50;

E-mail h.knops@irv.nl.

\section{Gerry Craddock, President Elect}

Central Remedial Clinic Ireland

Tel.: +3531 8057 523; Fax: +353 18335 496;

E-mail gcraddock@crc.ie.

\section{Anna-Liisa Salminen}

STAKES, Helsinki, Finland

Tel.: +358 93967 2089; Fax: +358 93967 2054;

E-mail anna-liisa.salminen@stakes.fi.

\section{Jan Persson}

CMT University of Linköping, Sweden

Tel.: +46 132249 93; Fax: +46 132249 95;

E-mail jan.persson@ihs.liu.se.

\section{Pier Luigi Emiliani}

Institute of Applied Physics, National Research

Council, Florence, Italy

Te.: +39 0554235 300; Fax: +39 0554235 286;

E-mail p.l.emiliani@ifac.cnr.it.

\section{Erland Winterberg}

Danish Centre, Taastrup, Denmark

Tel.: +45 439933 22; Fax: +45 425270 72;

E-mail e.winterberg@hmi.dk.

\section{AAATE Office}

c/o Danish Centre, Taastrup, Denmark

Tel.: +45 439933 22; Fax: +45 425270 72;

E-mail aaate@hmi.dk. 


\begin{tabular}{llll} 
AAATE National Contacts & & \\
\hline Country & Name & E-mail address & Affiliation \\
\hline Austria & Wolfgang Zagler & zw@ fortec.tuwien.ac.at & FORTEC Tech Univ Vienna \\
Belgium & Jan Engelen & jan.engelen@esat.kuleuven.ac.be & Catholic Univ Leuven \\
Denmark & Erland Winterberg & EWI@hmi.dk & Danish Centre \\
Croatia & Renata Hojanic & Hojanic@erf.hr & University of Zagreb \\
Finland & Juha Hautanen & juha.hautanen@jypoly.fi & Jyv äskylä Polytechnic \\
France & Alain Pruski & alain.pruski@lasc.univ-metz.fr & University of Metz \\
Germany & Christian Bühler & cb@ftb-volmarstein.de & FTB \\
Greece & Constantine Stephanidis & cs@csi.forth.gr & ICS-FORTH \\
Hungary & Andras Arato & arato@sunserv.kfki.hu & Lab.Speech Technology at KFKI \\
Ireland & Gerald Craddock & gcradd@crc.ie & Central Remedial Clinic. \\
Israel & Lawrence Normie & lnormie@jdc.org.il & GeronTech Israeli Ct AT \& Aging \\
Italy & Renzo Andrich & renzo.andrich@ siva.it & SIVA Fond. Don Gnocchi Onlus \\
Netherlands & Gert Jan Gelderblom & gj.gelderblom@irv.nl & iRv \\
Norway & Toril Bergerud Buene & Toril.BergerudBuene@ shdir.no & Delta Centre \\
Portugal & Luis Azevedo & pclma@alfa.ist.utl.pt & CAPS Tech Univ Lisbon \\
Slovakia & Dusan Simsik & Dusan.Simsik@tuke.sk & Tech Univ Košice \\
Slovenia & Crt Marincek & crt.marincek@mail.ir-rs.si & Univ Institute for Rehabilitation \\
Spain & Cristina R. Porrero & crodriguez@mtas.es & CEAPAT \\
Sweden & Hakan Neveryd & hakan.neveryd@certec.lth.se & Certec, Lund University. \\
UK & Nick Hine & nhine@computing.dundee.ac.uk & Dept Computing Univ. Dundee \\
\hline
\end{tabular}

